\title{
Fruit and vegetable consumption and anemia among adult non-pregnant women: Ghana Demographic and Health Survey
}

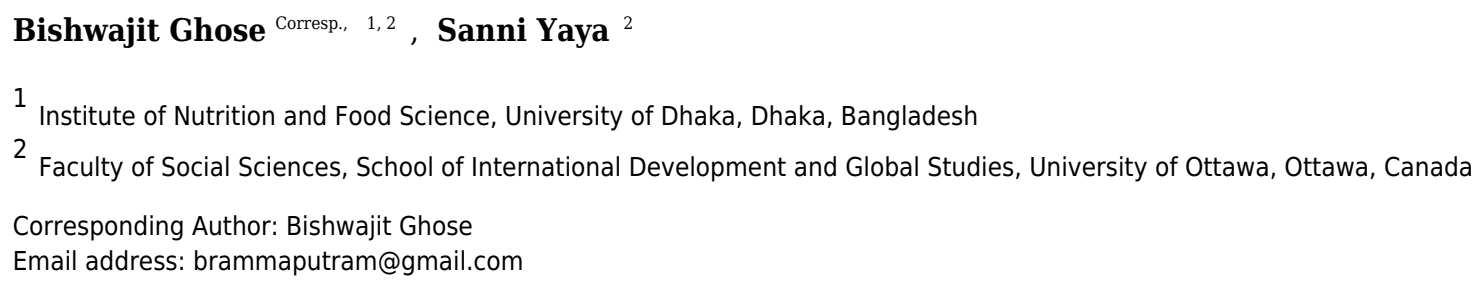

Background: Anemia is the most widely prevalent form of micronutrient deficiency that affects over a quarter of the global population. Evidence suggests that the burden of anemia is higher in the developing countries with women of reproductive age and children being the most at-risk groups. The most common causes are believed to be malnutrition and low bioavailability of micronutrients, which usually result from poor dietary habits and inadequate intake of food rich in micronutrients such as fresh fruits and vegetables. Regular consumption of F\&V was shown to have protective effect against NCDs, however evidence on this protective effect against micronutrient deficiency diseases are limited.

Objectives: 1) To measure the prevalence of anemia among adult non-pregnant women in Ghana, and 2) To investigate if there is any cross-sectional relationship between F\&V consumption and anemia. Methods This is a cross-sectional study based on data extracted from Ghana Demographic and Health Survey, 2008. Subjects were 4290 nonpregnant women aged between 15 and 49 years. Hemoglobin levels were measured by HemoCue ${ }^{\circledR}$ hemoglobin-meter. Association between anemia and $F \& V$ consumption was assessed by multivariable regression methods. Results Findings indicate that well over half $(57.9 \%)$ of the women were suffering from anemia of some level. Percentage of women consuming at least 5 servings of fruits and vegetables a day were $5.4 \%$ and $2.5 \%$ respectively. Results of multivariable analysis indicated that among urban women, consumption of $<5$ servings fruits/day was associated with significantly higher odds of severe $[A O R=9.27 ; 95 \% \mathrm{Cl}=5.15-16.70]$ and moderate anemia $[A O R=6.63 ; 95 \% \mathrm{Cl}=4.21$ 10.44], and consumption of $<5$ servings of vegetables/day was associated with higher odds of moderate anemia $[A O R=2.39 ; 95 \% \mathrm{Cl}=1.14-5.02]$ compared with those who consumed $>5$ servings/day. Conclusion The findings indicate that urban women who did not maintain WHO recommended level of $F \& V$ consumption bear a significantly higher likelihood of being moderate to severely anemic. 
1 Fruit and vegetable consumption and anemia among adult non-pregnant women:

2

3

4

5

6

$7 \quad 2$ Institute of Nutrition and Food Science, University of Dhaka, Dhaka 1000, Bangladesh

1,2 Bishwajit Ghose ${ }^{1}$ Sanni Yaya

${ }^{1}$ Faculty of Social Sciences, School of International Development and Global Studies, University of Ottawa

6

\section{Ghana Demographic and Health Survey}

Email addresses: 1 brammaputram@gmail.com

2 Sanni.yaya@uottawa.ca 
20 Background: Anemia is the most widely prevalent form of micronutrient deficiency

21 that affects over a quarter of the global population. Evidence suggests that the burden

22 of anemia is higher in the developing countries with women of reproductive age and

23 children being the most at-risk groups. The most common causes are believed to be

24 malnutrition and low bioavailability of micronutrients, which usually result from poor

25 dietary habits and inadequate intake of food rich in micronutrients such as fresh fruits

26 and vegetables. Regular consumption of F\&V was shown to have protective effect

27 against NCDs, however evidence on this protective effect against micronutrient

28 deficiency diseases are limited.

Objectives: 1) To measure the prevalence of anemia among adult non-pregnant women in Ghana, and 2) To investigate if there is any cross-sectional relationship between F\&V consumption and anemia.

Methods This is a cross-sectional study based on data extracted from Ghana Demographic and Health Survey, 2008. Subjects were 4290 non-pregnant women aged between 15 and 49 years. Hemoglobin levels were measured by HemoCue ${ }^{\circledR}$ hemoglobin-meter. Association between anemia and F\&V consumption was assessed by multivariable regression methods.

Results Findings indicate that well over half $(57.9 \%)$ of the women were suffering from anemia of some level. Percentage of women consuming at least 5 servings of fruits and vegetables a day were $5.4 \%$ and $2.5 \%$ respectively. Results of multivariable analysis indicated that among urban women, consumption of $<5$ servings fruits/day was associated with significantly higher odds of severe [AOR=9.27; 95\%CI=5.15-16.70] and moderate anemia $[\mathrm{AOR}=6.63 ; 95 \% \mathrm{CI}=4.21-10.44]$, and consumption of $<5$ servings of vegetables/day was associated with higher odds of moderate anemia [AOR=2.39; 95\%CI=1.14-5.02] compared with those who consumed $>5$ servings/day. 
45 Conclusion The findings indicate that urban women who did not maintain WHO 46 recommended level of $\mathrm{F} \& \mathrm{~V}$ consumption bear a significantly higher likelihood of being 47 moderate to severely anemic.

\section{Introduction}

Anemia affects more than a quarter of the world's population with most devastating impacts on women of reproductive age [1,2]. A systematic analysis of global anemia burden study reported that with a global prevalence of $32.9 \%$, anemia accounted for $8.8 \%$ of the total disability from all conditions in 2010 [2]. While the etiology of anemia is multifactorial, iron deficiency is believed to be the most common underlying cause [3] as half of the global anemia cases are assumed to be attributable to iron deficiency [4]. Several other micronutrients (e.g. vitamins A, B12 or folate) were also found to be important factors in the pathophysiology of anemia, yet these associations remain to be confirmed by interventional studies [1,5]. Iron deficiency ranks number 9 among 26 risk factors included in the Global Burden of Disease (GBD 2000), and accounts for about 841,000 deaths and 35,057,000 disability-adjusted life years lost [4]. Although the prevalence and susceptibility of anemia differ substantially across sex and age groups, women of reproductive age are regarded as a research priority because of the increased exposure to pregnancy related complications e.g. preterm labor, placental abruption, low birth weight (LBW), and infant and maternal mortality $[2,6,7]$.

Globally, there has been a rising concern regarding the consequences of anemia and other micronutrient deficiency disorders (hidden hunger) on maternal and infant health. Over the course of last two-three decades, significant progress has been achieved towards the elimination of vitamin A and iodine deficiencies, however progress has 
70 been uneven toward reducing the burden of iron-deficiency anemia (IDA) across

71 different regions of the world as micronutrient deficiencies continue to be a serious

72 public health issue especially in the South Asia and Sub-Saharan Africa [4,8,9].

73 According to $\mathrm{WHO}$ estimates, the prevalence rates of anemia for non-pregnant women

74 are $47.5 \%$ in Africa (highest globally), which makes it of severe public health

75 significance in the region [8].

76 Deficiencies of certain micronutrients (Iron, Vitamin-A, Iodine) have been a top 77 international health priority for decades, achieving the prevention of which has been considered as one the most important achievable health related goal [11]. There is a growing body of research dedicated to investigating the underlying determinants and sustainable interventions of micronutrient deficiencies. The theme that commonly emerge in the current scientific literature is a food based approach in the context of sustainable agriculture aimed at promoting dietary diversity diversification for longterm intervention of deficiency diseases at population level [12,13]. In high anemia prevalent countries e.g. Bangladesh and India, iron supplementation and increased intake of iron rich food have been applied as a strategy to combat anemia among young women. Poor dietary intake and low bioavailability of iron (especially non-heme) in resource-poor countries are considered to be the key determinants of low body iron reserve and resultant anemia [10]. As dietary factors appear to be the major contributors to iron and other deficiencies and subsequent development of anemia [3,12], food based interventions, such as diet diversification by including seasonal $\mathrm{F} \& \mathrm{~V}$, are usually proposed as a sustainable solution to this persistent problem $[3,13,14]$.

The protective mechanism of $F \& V$ against non-communicable chronic diseases (NCDs) has been well documented [15-17]. However, little is known regarding the relationship between $F \& V$ intake and anemia or other deficiency diseases. The benefits of $F \& V$ consumption in the prevention of NCDs has found to be rooted to numerous 
96 phytochemicals they contain which are essential for optimum physiological functioning

97 and prevention of development of metabolic symptoms [18]. For Iron Deficiency

98 Anemia (IDA), F\&V exert the beneficial effects mainly through their high non-heme 99 iron content, and through ascorbic acid content (citrus fruits) which contributes to 100 greater bioavailability of iron by functioning as a stimulating factor in its absorption $101[19,20]$. Though heme iron has higher bioavailability than non-heme iron, the latter 102 occurs in much greater quantity in natural food and thus generally contributes more to 103 iron nutrition than heme-iron food [19]. Apart from acting as a direct source of dietary 104 iron, $\mathrm{F} \& \mathrm{~V}$ consumption exerts the beneficial effects on anemia through their relatively 105 higher vitamin- $C$ content which enhances the bioavailability of iron in the diet. Another crucial micronutrient that makes F\&V consumption an important component to consider when it comes to the pathophysiology of anemia is folate (folic acid). Folic acid deficiency related anemia is a commonly encountered health concern among pregnant women in developing countries, and are routinely advised to take folate or iron-folate supplement during antenatal visits when dietary intake of these elements seem to be insufficient.

Compared to animal based foods, F\&V deserve more attention in the context of micronutrient deficiency and dietary diversification especially for their cheaper availability, relatively lower environmental footprints. In addition, F\&V has proven benefits in the prevention of several NCDs to which meat consumption has found to be a risk factor (e.g. cancer, diabetes, cardiovascular diseases) [21-23]. To this regard, we conducted this study on F\&V consumption only to explore whether or not the level of consumption was associated with anemia among non-pregnant women in Ghana. As country representative data on anemia is hard to obtain for developing countries, we used secondary data from Ghana Demographic and Health Survey (GDHS 2008) which provides information on anemia and $F \& V$ consumption among women aged between 
122 15-49 years. The outcomes of this study are expected to contribute to the current

123 literature and future researches by providing insights on how F\&V consumption relates

124 to anemia, as well as useful information for anemia prevention strategies among non125 pregnant women in Ghana and other countries in the region.

\section{Methods}

\section{Data source}

129

130

131

132

133

134

135

136

137

138

139

140

141

142

143

144

145

146

Data for this study were obtained from Ghana Demographic and Health Survey (GDHS) that was conducted in 2008. The 2008 GDHS is the fifth of this kind in the country that aimed to provide data to monitor the population and health situation in Ghana under the auspices of Demographic and Health Survey of USAID. The survey included a range of demographic, socioeconomic, health knowledge and behavior related themes. The survey was carried out by the Ghana Statistical Service (GSS) and the Ghana Health Service (GHS) with technical assistance of ICF Macro, (an ICF International Company) through the MEASURE DHS program and financial support from the United States Agency for International Development (USAID). The fieldwork lasted from September 8 to November 25 of the year 2008. The survey included three different types questionnaires: for Household, Women, and Men. The dataset for the present study was from the questionnaire for Women.

\section{Sampling strategy}

The 2008 GDHS was a household-based survey, implemented in a representative probability sample of more than 12,000 households from urban and rural areas in each of the 10 regions in Ghana. A two-stage sampling design was utilised. The first stage involved selection of cluster from a master sampling frame, and the second stage involved selection of households from the clusters. For clusters selection, a master 
147 sampling frame was used that was designed during the 2000 Ghana Population and

148 Housing Census. In total 412 clusters were selected from the master sampling frame.

149 In the second stage, 30 households were selected systematically from each cluster.

150 Weights were also calculated taking into consideration the non-responses at various

151 level to ensure the sample is representative of the general population. Of the 12,323

152 households selected in the sample, 11,913 were occupied at the time of the

153 fieldwork. A total of 5,096 eligible women were identified in the households and were

154 selected for individual interview. Finally, interviews were successfully completed with

1554,916 of the women with a response rate of $97 \%$. More details regarding the sampling

156 techniques are available elsewhere [24].

\section{Hemoglobin testing for anemia}

158 For GDHS 2008, diagnosis of anemia was performed by using the HemoCue® blood 159 hemoglobin testing system. Hemoglobin testing is the routinely used method for 160 anemia diagnosis. HemoCue ${ }^{\circledR}$ (HemoCue Inc., Mission Viejo, CA, USA) is a user 161 friendly and highly reliable point-of-care testing (POCT) system and one of the most 162 commonly utilized of hemoglobin testing devices [25]. The protocol for hemoglobin 163 testing was approved by the ICF Macro Institutional Review Board (IRB) in Calverton, 164 Maryland, USA and the Ghana Health Service Ethical Review Committee in Accra, 165 Ghana. Trained surveyors were responsible for undertaking the HemoCue® test 166 through finger prick method. Women from half of the households who participated in 167 the 2008 GDHS survey were selected (those who gave consent) for anemia test.

\section{Variables selection}

169 Outcome variable: Anemia status (measured in terms of $\mathrm{Hb}$ concentration) was the 170 outcome variable in this study. Anemia was categorized as per the cut-off points 
171 recommended by the WHO for women above age 15 years: Mild anemia= 10-11.9 g/dl;

172 moderate anemia= 7-9.9 g/dl; severe anemia $=<7.0 \mathrm{~g} / \mathrm{dl}$, non-anemic= $\geq 12 \mathrm{~g} / \mathrm{dl}$ [26].

\section{Independent variables}

174 Levels of fruit and vegetable consumption were the main independent variables in this 175 study. Respondents were asked separately how many servings of fruits and vegetables

176 they consume on a typical day. For both fruits and vegetables, the answers were 177 categorized according to WHO recommendations for adult individuals as: $\geq 5$ servings 178 of fruits/day = adequate, and $<5$ servings of fruits/day= inadequate.

179 Guided by existing literature on dietary intervention and determinants of 180 anemia/micronutrient deficiency and availability on the datasets, we have considered 181 several socioeconomic, demographic and health behaviour related variables as potential 182 confounders, and were categorized as- Age: 15-19, 20-24, 25-29, 30-34, 35-39, 40-44, 4549; Marital status: Never married, Married, Living together, Other; Religion: Christian, Moslem, Other; Educational attainment: No education, Primary, Secondary, Higher; Wealth status: Poorest, Poorer, Middle, Richer, Richest: BMI: Underweight, Normal weight, Overweight, Obese [13-15, 19, 24,25,26,27]. Body mass index (BMI) was defined as weight $(\mathrm{kg})$ divided by height $\left(\mathrm{m}^{2}\right)$, and was categorized as per WHO definitions: $<18.49=$ Underweight, $18.5-24.9=$ Normal weight, $25-29.9=$ Overweight,$>30=$ Obese. Wealth index was included in the study as it is used universally in DHS studies as a proxy indicator for economic status of households that is consistent with expenditure and income measures [24]. The calculation of the wealth index involves assigning a factor score for a set of household possessions (e.g. TV, Radio, bicycle, and housing quality e.g. type of floor, wall, and roof) which is generated through principal component analysis (PCA). The scores are then summed and standardized for each household which places them in a continuous scale based on the individual scores.

196 Once calculated, the scores are then categorized into quintiles where each household 
197 falls into a category, with the lowest scores representing the poorest and highest 198 representing the richest households [7].

\section{Statistical analysis}

201

202

203

204

205

206

207

208

209

210

211

212

213

214

215

216

217

218

219

220

221

All analyses were conducted with SPSS 21 for Mac (SPSS Inc., Chicago, IL, USA). Initial checks were performed for missing values, outliers and multicollinearity issues. Sample weight was applied (as provided in the dataset) before analysing the dataset to account for any variations in the response rates across survey regions. Results were stratified by place of residency, as people in urban and rural areas have been shown to differ significantly in terms of exposure various health risk factors, lifestyle and health related behaviours [28]. Basic sample characteristics (Socioeconomic, demographic, behavioural) were presented as frequencies and percentages. Pearson's Chi-square tests were performed to check for statistical association between anemic and non-anemic groups and $F \& V$ consumption status plus all other covariates. Only those variables that were found significant in Chi-square tests at $p<0.25$ were included in the multivariable regression model. The results of regression analysis were presented as odds ratios and corresponding 95\% confidence intervals (CI). All tests were two-tailed, and statistical significance was set at $\mathrm{p}<0.05$.

\section{Ethics approval}

All participants gave informed consent before taking part in the interview. The ICF International was responsible for ensuring that the survey complies with the U.S. Department of Health and Human Services regulations for the protection of human subjects, and the host country ensures that the survey complies with laws and norms of the nation [24]. Further approval for using DHS datasets are unnecessary since they are available in the public domain without any identifiable information of the participants. 


\section{Results:}

\section{Profile of the respondents}

225 Basic demographic and socioeconomic characteristics of the sample population were

226 presented in table 1. Mean age of the participants were 29.3 years (SD 9.8). Both in 227 urban and rural areas, majority of the women were aged between 15 to 29 years. Less 228 than half of the women were married $(45.6 \%)$, and almost four-fifth belonged to 229 Christian faith (78.5\%). One-fifth of the women had no formal education (20.6\%), and 230 majority had secondary level qualification (55.5\%). Women in urban areas had higher 231 rates of secondary (67.2\% Vs 44.4\%) and higher than secondary (6.1\% Vs $1.1 \%)$ level 232 educational qualification. About one-third of the women reported living in poorest to 233 poorer households (33.6\%), while $22.8 \%$ were

\section{4 (Table 1)}

236 living in households with highest wealth status. Regarding body weight status, $8.4 \%$ of 237 the women were underweight, while the rate of overweight and obesity were 238 respectively $20 \%$ and $10 \%$. Chi-square tests also revealed significant urban-rural 239 disparities in all the demographic and socioeconomic variables listed in Table-1, 240 whereas for the behavioral factors the difference was significant for fruit consumption 241 only (Table-2).

244 Prevalence of health related behaviours (smoking, drinking, F\&V intake) and anemia 
245 The prevalence of alcohol consumption was $18.1 \%$, while that of tobacco smoking was

246 almost nil (0.1\%). Regarding fruit and vegetable intake, only $5.4 \%$ and $2.5 \%$ women

247 reported consuming more than five servings of fruits and vegetables respectively.

248 Significantly different prevalence was observed between urban and rural women in

249 terms of adequate consumption ( 5 or $>5$ servings/day) of fruits, but not vegetables. The

250 prevalence of anemia was considerably high as more than half of the women $(57.9 \%)$

251 had anemia of some level. The prevalence of severe, moderate and mild anemia was

252 respectively $1.6 \%, 16.1 \%$ and $40.2 \%$ (Table 2). Women in rural areas had higher

253 prevalence of anemia of all three levels compared with their urban counterparts.

254

255

256 (Table 2)

257

258

259

Bivariate association between anemia and the socioeconomic, demographic and health behavioral characteristics

260 We examined bivariate differentials to explore the differences in anemia prevalence 261 across the categories of the explanatory variables. Table 3 indicates that the prevalence 262 of severe anemia was highest among women aged 45-49 years, while that of moderate 263 and mild anemia was highest among those in the age group of 15-19 years. No 264 significant difference was found between anemia and marital status and religion. 265 However; educational attainment $(\mathrm{p}=0.001)$, household wealth status $(\mathrm{p}=0.04)$, and BMI $266(\mathrm{p}<0.001)$ appeared to be significantly associated with anemia. Table 3 also indicates that

267 the likelihood of being anemic (all three levels) was higher among those who had 268 secondary level education, were from middle 
271 wealth status households, and were underweight. Regarding the health behavior 272 related characteristics, significant association was found between anemia with fruits 273 and vegetable consumption, but not with tobacco smoking and alcohol drinking (Table 274 4).

275

276

277

278

279

280

(Table 4)

281

282

283

284

Multivariable analysis

285 Results of multivariable analysis for measuring the association between F\&V 286 consumption and mild, moderate and severe anemia among urban and rural women 287 were shown in Table 5. Results indicate that inadequate fruit consumption was 288 associated with higher odds of severe and moderate anemia, but not mild anemia 289 among urban women. No statistically significant association was observed between 290 fruits and vegetable consumption and anemia among rural women. Compared with 
291 women who consumed at least five servings of fruits per day, the odds of being

292 severely anemic was over 9 times [AOR=9.28; 95\%CI=5.15-16.70] and of being

293 moderately anemic was over 6 times $[\mathrm{AOR}=6.64 ; 95 \% \mathrm{CI}=4.21-10.44]$ among those who

294 reported consuming less than five servings of fruits a day. Regarding vegetable 295 consumption, women who did not consume at least five servings a day had 2.4 $296[\mathrm{AOR}=2.39 ; 95 \% \mathrm{CI}=1.14-5.02]$ times higher odds of being moderately anemic compared 297 to those who consumed five servings of fruits per day.

298 (Table 5)

\section{Discussion}

301 The aim of the present study was to measure the prevalence of anemia, and its 302 association with fruits and vegetables consumption in a nationally representative non303 pregnant women sample in Ghana. Results indicated that over half of the women were 304 living with anemia of some degree (Severe: 1.6\%, Moderate: 16.1\%, Mild: 40.2\%), which 305 is higher than average for African countries (57.9\% Vs 47.5\%) [8]. According to WHO 306 classifications, at this prevalence rate anemia qualifies to be of severe public health 307 significance in the country [8]. Not surprisingly, the prevalence rates of all three levels 308 of anemia in the rural areas were higher than in urban areas. Regarding F\&V intake, it appeared that most of the women did not maintain adequate amount (in line with 310 WHO recommendation) of consumption as only $5.4 \%$ and $2.5 \%$ women reported 311 consuming at least five servings of fruits and vegetables respectively. Percentage of 312 women who consumed at least five servings of fruits was higher in urban areas, 313 whereas that of vegetable was slightly higher in rural areas. Our findings also indicated 314 that compared to women who consumed at least five servings of fruits and vegetables, 315 those who consumed less than five servings of fruits and vegetables had higher odds of 
316 suffering from severe and moderate anemia and moderately anemia respectively.

317 However, the association was statistically significant for urban women only. It is hard

318 to explain this urban-rural variation regarding this association within the scope of the

319 current study. It is assumable the etiology of might be as well linked to factors other

320 than dietary ones such as parasitic infestations or inflammatory diseases to which rural

321 population are particularly vulnerable [29].

322 Despite its significant public health importance, research evidence on anemia and the 323 associated risk factors remain scarce in Ghana. No comparable nationwide estimates are 324 available as yet for non-pregnant women. A cross-sectional study among pregnant 325 women based on Accra found high rates anemia (All cause anemia $=34 \%$, Iron 326 deficiency anemia $=7.5 \%$ ) [30]. Although evidence from countries in sub-Saharan Africa

327 is scarce, similarly high prevalence rates were reported in South Asian countries e.g.

328 India (mild anemia $=32.4 \%$, moderate anemia $=14.19 \%$, severe anemia $=2.2 \%$ ) [31], and in

329 Bangladesh (mild anemia $=35.5 \%$, moderate anemia $=5.6 \%$, severe anemia $=0.2 \%$ ) which 330 are recognised as global hotspots for micronutrient deficiency diseases [32]. This study 331 recognizes lack of prior researches on the association between fruit and vegetable 332 consumption and anemia among women. Only a recent Brazilian study on children 333 aged 4-10 years reported that children who consumed lower than usual amount of F\&V 334 were twice as likely to have micronutrient deficiencies compared to children with usual 335 F\&V consumption [33]. The reason why this topic has failed to receive adequate 336 research attention is probably because of the absence of any universal consensus on the 337 level of $\mathrm{F} \& \mathrm{~V}$ intake for optimum nutrition. Another inherent complexity in assessing 338 the impact of $F \& V$ consumption on micronutrient deficiency outcomes is inadequate 339 knowledge base regarding the dietary and physiological factors limiting and 340 stimulating absorption of certain types of micronutrients [3]. 
341 Besides the poor level of $\mathrm{F} \& \mathrm{~V}$ consumption, there were also indications of urban-rural

342 differences in the patterns of $\mathrm{F} \& \mathrm{~V}$ intake. The noticeably lower intake of $\mathrm{F} \& \mathrm{~V}$ might be

343 because of the nutrition transition the country is undergoing [34], which is being led by

344 rapid urbanization, improving living standards and changing food policy dynamics

345 [35,36]. The shift in dietary habits such as increased intake of convenience foods and

346 lower intake of fresh F\&V have raised concerns regarding the nutritional status of the

347 population in both developing and developed countries [34,36]. Though the present

348 study does not provide any insight on dietary preferences among the participants, the

349 dietary transition and low F\&V consumption [34] might offer some explanation on the

350 high prevalence of anemia among the participants.

351 The public-health importance of addressing micronutrient deficiencies has been

352 underscored by major international nutrition conferences and agencies who have

353 played critical roles in advocating for and raising awareness among policymakers and

354 the general population regarding these issues at the global, regional, and national levels

$355[5,9]$. There is a growing body of research confirming that the underlying determinants

356 of micronutrient deficiencies, and a sustainable solution to this persistent problem are

357 best understood by taking into consideration the complex interplay of health,

358 agricultural and sociopolitical factors. Dietary diversification especially by inclusion of

359 seasonal fruits and vegetables, as opposed to supplementation and fortification, has

360 been proposed to be a more culturally adaptable and a sustainable strategy that hold of

361 the potential to address multiple micronutrient deficiencies simultaneously [14].

362 Findings of this study support the consensus that optimum consumption of F\&V might

363 prove beneficial for addressing the burden of anemia among Ghanaian women.

364 As far as we are concerned, this is the first study to report on $\mathrm{F} \& \mathrm{~V}$ consumption in

365 association with anemia among non-pregnant women. Sample size was considerably

366 large and the findings are generalizable for non-pregnant women population aged 
367 between 15-49 years. Diagnosis and categorization of anemia was based on standard

368 procedures. Data were analysed with rigorous methods and reported as per STROBE

369 guidelines. Despite the strengths, there are some important limitations that needs to be

370 considered when interpreting the findings. Firstly, the data were secondary which

371 means that we could not control the measurement and selection of variables and

372 confounders. The cross-sectional nature of the data precludes making any causality

373 regarding the relationship between outcome and explanatory variables. Therefore, the

374 association between fruit and vegetable consumption and anemia provides no

375 indication of direction, which may be bidirectional. It is possible the anemia affects taste

376 acuity/appetite which might reduce the intake of fruits and vegetables. We were also

377 limited in our ability to determine the types of $\mathrm{F} \& \mathrm{~V}$ that were consumed (diversity in

$378 \mathrm{~F} \& \mathrm{~V}$ intake). This is an important concern since the micronutrient content of $\mathrm{F} \& \mathrm{~V}$ varies

379 considerably by type, and across seasons and regions. As fruit and vegetables

380 consumption was self-reported, there remains the chance of over/under reporting. Last

381 but not least, we could not adjust the analysis for the presence of non-dietary factors

382 that are known contributing factors to anemia (e.g. problems with absorption, parasitic

383 infestation, drug toxicity or inflammatory diseases) which might have caused any

384 misinterpretation of the prevalence of anemia.

385

386 Conclusion

387 This study concludes that the overall prevalence of anemia among non-pregnant 388 women in Ghana was higher than that of African country average. Based on the WHO 389 classification, the prevalence is categorized as a severe public health concern. Our study 390 also found a positive association between F\&V consumption and anemia among non391 pregnant women living in the urban areas. Results of this study might be of crucial 392 importance for public health programs targeting anemia prevention in the country. 
393 From the findings, it is also recommendable that national nutrition programs focus on 394 developing strategies to promote $\mathrm{F} \& \mathrm{~V}$ consumption as a part of the policy to address 39 anemia among adult non-pregnant women especially in urban areas. To provide more 396 precise estimates of national anemia prevalence, future studies should take into consideration other disease conditions that might have affected the prevalence of 398 anemia.

\section{Abbreviations}

400

Ghana Demographic and Health Survey (GDHS), Non-communicable chronic diseases 401 (NCDs); Iron-deficiency anemia (IDA); Millennium Development Goals (MDGs).

\section{References}

1. Aurélie A. Righetti, Ahou-Yah G. Koua, Lukas G. Adiossan, Dominik Glinz, 406 Richard F. Hurrell, Eliézer K. N'Goran, Sébastien Niamké, Rita Wegmüller, and Jürg Utzinger. Etiology of Anemia Among Infants, School-Aged Children, and Young Non-Pregnant Women in Different Settings of South-Central Côte d'Ivoire. Am J Trop Med Hyg. 2012 Sep 5; 87(3): 425-434.

2. Nicholas J. Kassebaum,corresponding, Rashmi Jasrasaria, Mohsen Naghavi, Sarah K. Wulf, Nicole Johns, Rafael Lozano, Mathilda Regan, David Weatherall, David P. Chou, Thomas P. Eisele, Seth R. Flaxman, Rachel L. Pullan, Simon J. Brooker, Christopher J. L. Murray. A systematic analysis of global anemia burden from 1990 to 2010. Blood. 2014 Jan 30; 123(5): 615-624.

3. Kathryn L. Beck, Cathryn A. Conlon, Rozanne Kruger, and Jane Coad. Dietary Determinants of and Possible Solutions to Iron Deficiency for Young Women 
417

418

419

420

421

422

423

424

425

426

427

428

429

430

431

432

433

434

435

436

437

438

439

440

441

Living in Industrialized Countries: A Review. Nutrients. 2014 Sep; 6(9): 37473776.

4. Stoltzfus RJ. Iron deficiency: global prevalence and consequences. Food Nutr Bull. 2003 Dec;24(4 Suppl):S99-103.

5. Haider BA, Bhutta ZA. Neonatal vitamin A supplementation for the prevention of mortality and morbidity in term neonates in developing countries. Cochrane Database Syst Rev. 2011 Oct 5; (10):CD006980.

6. Rasmussen KJ. Is There a Causal Relationship between Iron Deficiency or IronDeficiency Anemia and Weight at Birth, Length of Gestation and Perinatal Mortality? Nutr. 2001 Feb; 131(2S-2):590S-601S; discussion 601S-603S.

7. Ghose B, Feng D, Tang S, Yaya S, He Z, Udenigwe O, Ghosh S, Feng Z. Women's decision-making autonomy and utilisation of maternal healthcare services: results from the Bangladesh Demographic and Health Survey. BMJ Open. 2017 Sep 7;7(9):e017142.

8. De Benoist B, McLean E, Egli, Cogswell M, editors. Worldwide prevalence of anaemia 1993-2005: WHO global database on anaemia; Geneva: World Health Organization; 2008.

9. Dalmiya N, Schultink W. Combating hidden hunger: the role of international agencies. Food Nutr Bull. 2003 Dec;24(4 Suppl):S69-77

10. Kazi M. Jamil, Ahmed Shafiqur Rahman, P.K. Bardhan, Ashraful Islam Khan, Fahima Chowdhury, Shafiqul Alam Sarker, Ali Miraj Khan, Tahmeed Ahmed. Micronutrients and Anaemia. J Health Popul Nutr. 2008 Sep; 26(3): 340-355.

11. G F Maberly, F L Trowbridge, R Yip, K M Sullivan, and C E West. Programs Against Micronutrient Malnutrition: Ending Hidden Hunger. Annual Review of Public HealthVol. 15: 277-301. 
442

443

444

445

446

447

448

449

450

451

452

453

454

455

456

457

458

459

460

461

462

463

464

465

466

467

12. Francesco B, Jessica F, Emile F. The Role of Food and Nutrition System Approaches in Tackling Hidden Hunger. Int J Environ Res Public Health. 2011 Feb; 8(2): 358-373.

13. Madhavan K. Nair, Little Flower Augustine, Archana Konapur. Front Public Health. 2015; 3: 277.

14. Tontisirin K, Nantel G, Bhattacharjee L. Food-based strategies to meet the challenges of micronutrient malnutrition in the developing world. Proc Nutr Soc. 2002 May; 61(2):243-50.

15. Liu S, Manson JE, Lee IM, Cole SR, Hennekens CH, Willett WC, Buring JE. Fruit and vegetable intake and risk of cardiovascular disease: the Women's Health Study. Am J Clin Nutr October 2000 vol. 72 no. 4 922-928.

16. Dauchet L, Amouyel P, Hercberg S, Dallongeville J. Fruit and Vegetable Consumption and Risk of Coronary Heart Disease: A Meta-Analysis of Cohort Studies. J. Nutr. 2006 136: 2588-2593

17. Hartley L, Igbinedion E, Holmes J, Flowers N, Thorogood M, Clarke A, Stranges S, Hooper L, Rees K. Increased consumption of fruit and vegetables for the primary prevention of cardiovascular diseases. Cochrane Database Syst Rev. 2013 Jun 4;(6):CD009874.

18. Sana Syed, O. Yaw Addo, Vanessa De la Cruz-Góngora, Fayrouz A. Sakr Ashour, Thomas R. Ziegler, and Parminder S. Suchdev. Determinants of Anemia among School-Aged Children in Mexico, the United States and Colombia. Nutrients. 2016 Jul; 8(7): 387.

19. Monsen ER, Hallberg L, Layrisse M, Hegsted DM, Cook JD, Mertz W, Finch CA. Estimation of available dietary iron. Am J Clin Nutr. 1978;31:134-41.

20. Bothwell TH, Baynes RD, MacFarlane BJ, MacPhail AP. Nutritional iron requirements and food iron absorption. J Intern Med. 1989;226(5):357-65. 
468

469

470

471

472

473

474

475

476

477

478

479

480

481

482

483

484

485

486

487

488

489

490

491

492

493

494

21. Jeanine M Genkinger, Anita Koushik. Meat Consumption and Cancer Risk. PLoS Med. 2007 Dec; 4(12): e345.

22. Neal B, Susan L, Caroline T. Meat Consumption as a Risk Factor for Type 2 Diabetes. Nutrients. 2014 October 16; 6(10): 4317.

23. Kaluza J, Wolk A, Larsson SC. Red meat consumption and risk of stroke: a metaanalysis of prospective studies. Stroke. 2012 Oct;43(10):2556-60. 2012 Jul 31.

24. Ghana Statistical Service (GSS), Ghana Health Service (GHS), and ICF Macro. 2009. Ghana Demographic and Health Survey 2008. Accra, Ghana: GSS, GHS, and ICF Macro.

25. Ghose Bishwajit, Sanni Yaya, Shangfeng Tang, Akmal Hossain, Yang Fan, Mahmuda Akter, Zhanchun Feng. Association of Living Arrangement Conditions and Socioeconomic Differentials with Anemia Status among Women in Rural Bangladesh. Biomed Res Int. 2016; 2016: 4571686.

26. Ghose B, Tang S, Yaya S, Feng Z. Association between food insecurity and anemia among women of reproductive age. (2016) PeerJ 4:e1945.

27. Bishwajit G, Sanni Y, Shangfeng T. Anemia Status in Relation to Body Mass Index Among Women of Childbearing Age in Bangladesh. Asia Pacific Journal of Public Health. Vol 28, Issue 7, 2016.

28. Mark S. Eberhardt, Elsie R. Pamuk. The Importance of Place of Residence: Examining Health in Rural and Nonrural Areas. Am J Public Health. 2004 October; 94(10): 1682-1686.

29. Alexis Ponder and Millie D Long. A clinical review of recent findings in the epidemiology of inflammatory bowel disease. Clin Epidemiol. 2013; 5: 237-247.

30. Cyril Engmanna, Richard Adanub, Tsui-Shan Luc, Carl Bosea, Betsy Lozoffd. Anemia and iron deficiency in pregnant Ghanaian women from urban areas. International Journal of Gynecology \& Obstetrics. Volume 101, Issue 1, April 2008, Pages 62-66. 
495

496

497

498

499

500

501

502

503

504

505

506

507

508

509

510

511

512

513
31. Bentley ME, Griffiths PL. The burden of anemia among women in India. Eur J Clin Nutr. 2003 Jan;57(1):52-60.

32. Kamruzzaman M, Rabbani MG, Saw A, Sayem MA, Hossain MG. Differentials in the prevalence of anemia among non-pregnant, ever-married women in Bangladesh: multilevel logistic regression analysis of data from the 2011 Bangladesh Demographic and Health Survey. BMC Womens Health. 2015; 15: 54.

33. Augusto RA, Cobayashi F, Cardoso MA; ACTION Study Team. Associations between low consumption of fruits and vegetables and nutritional deficiencies in Brazilian schoolchildren. Public Health Nutr. 2015 Apr;18(5):927-35.

34. Bishwajit G, Ide S, Hossain MA, Safa MN. Trade Liberalization, Urbanization and Nutrition Transition in Asian Countries. (2014) J Nutr Health Food Sci 2(1): 5.

35. Ghose B. Nutrition transition in South Asia: the emergence of non-communicable chronic diseases. F1000Res. 2015; 4: 8.

36. Samuel Agyei-Mensah, Ama de-Graft Aikins. Epidemiological Transition and the Double Burden of Disease in Accra, Ghana. J Urban Health. 2010 Sep; 87(5): 879_ 897. 
Table $\mathbf{1}$ (on next page)

Participant characteristics (Socioeconomic and demographic). GDHS 2008. 
Table 1: Participant characteristics (Socioeconomic and demographic). GDHS 2008.

\begin{tabular}{|c|c|c|c|c|}
\hline Variables & Total (4290) & Urban (2090) & Rural (2200) & $\mathbf{P}$ \\
\hline Age & 29.3 (SD 9.8) & 28.62 ( SD 9.6) & 29.42 (SD 9.8) & 0.019 \\
\hline $15-19$ & $933(21.7)$ & $459(22.0)$ & $474(21.5)$ & \\
\hline $20-24$ & $734(17.1)$ & $388(18.6)$ & $346(15.7)$ & \\
\hline $25-29$ & $704(16.4)$ & 347 (16.6) & $357(16.2)$ & \\
\hline $30-34$ & $532(12.4)$ & $272(13.0)$ & $260(11.8)$ & \\
\hline $35-39$ & $572(13.3)$ & $265(12.7)$ & $307(14.0)$ & \\
\hline $40-44$ & $427(9.9)$ & $186(8.9)$ & $241(10.9)$ & \\
\hline $45-49$ & $387(9.0)$ & $172(8.2)$ & $215(9.8)$ & \\
\hline Marital status & & & & 0.004 \\
\hline Never married & $1440(33.6)$ & $754(36.1)$ & $686(31.2)$ & \\
\hline Married & $1956(45.6)$ & $910(43.5)$ & $1046(47.5)$ & \\
\hline Living together & $492(11.5)$ & $225(10.7)$ & $267(12.1)$ & \\
\hline Other & $403(9.4)$ & $44(2.1)$ & $201(9.1)$ & \\
\hline Religion & & & & $<0.001$ \\
\hline Christian & $3370(78.5)$ & $1680(80.4)$ & $1689(76.8)$ & \\
\hline Moslem & $613(14.3)$ & $364(17.4)$ & 249 (11.3) & \\
\hline Other & $307(7.2)$ & $45(2.2)$ & $262(11.9)$ & \\
\hline $\begin{array}{l}\text { Educational } \\
\text { attainment }\end{array}$ & & & & $<0.001$ \\
\hline No education & $883(20.6)$ & $222(10.6)$ & $661(30.0)$ & \\
\hline Primary & $875(20.4)$ & $336(16.1)$ & $539(24.5)$ & \\
\hline Secondary & $2382(55.5)$ & 1405 (67.2) & $977(44.4)$ & \\
\hline Higher & $151(3.5)$ & $127(6.1)$ & $24(1.1)$ & \\
\hline Wealth status & & & & $<0.001$ \\
\hline Poorest & $666(15.5)$ & $16(0.8)$ & $650(29.5)$ & \\
\hline Poorer & $775(18.1)$ & $93(4.5)$ & $682(31.0)$ & \\
\hline Middle & $874(20.4)$ & $376(18.0)$ & $497(22.6)$ & \\
\hline Richer & $999(23.3)$ & $721(34.5)$ & $277(12.6)$ & \\
\hline Richest & $977(22.8)$ & $883(42.2)$ & $94(4.3)$ & \\
\hline BMI & & & & $<0.001$ \\
\hline Underweight & $360(8.4)$ & $125(6.0)$ & $235(10.7)$ & \\
\hline Normal weight & $2643(61.6)$ & $1123(53.7)$ & $1520(69.1)$ & \\
\hline Overweight & $859(20.0)$ & $531(25.4)$ & $329(14.9)$ & \\
\hline Obese & $427(10.0)$ & $312(14.9)$ & $116(5.3)$ & \\
\hline
\end{tabular}


N.B. p-values (from Chi-square tests) indicate the significance in the differences between urban and rural sample for the explanatory variables. 


\section{Table 2 (on next page)}

Health related behavior and body weight status of the sample population. GDHS 2008. 
Table 2: Health related behavior and body weight status of the sample population. GDHS 2008.

\begin{tabular}{|c|c|c|c|c|}
\hline Variables & Total & Urban & Rural & p-value \\
\hline Alcohol consumption & & & & 0.408 \\
\hline No & $3514(81.9)$ & $1715(82.1)$ & $1799(81.7)$ & \\
\hline Yes & $776(18.1)$ & $375(17.9)$ & $402(18.3)$ & \\
\hline Smokes cigarettes & & & & 0.293 \\
\hline No & $4286(99.9)$ & 2087 (99.9) & $2199(99.9)$ & \\
\hline Yes & $4(0.1)$ & $3(0.1)$ & $1(0.1)$ & \\
\hline Fruit consumption & & & & $<0.001$ \\
\hline$<5$ servings/day & $4057(94.6)$ & $1950(93.3)$ & $2107(95.8)$ & \\
\hline 5 or $>5$ servings/day & $233(5.4)$ & $140(6.7)$ & $93(4.2)$ & \\
\hline $\begin{array}{l}\text { Vegetable } \\
\text { consumption }\end{array}$ & & & & 0.269 \\
\hline$<5$ servings/day & $4184(97.5)$ & $2042(97.7)$ & $2142(97.3)$ & \\
\hline 5 or $>5$ servings/day & $106(2.5)$ & $48(2.3)$ & $58(2.7)$ & \\
\hline Anemia level & & & & 0.001 \\
\hline Severe & $68(1.6)$ & $27(1.3)$ & $41(1.9)$ & \\
\hline Moderate & $691(16.1)$ & $332(15.9)$ & $360(16.3)$ & \\
\hline Mild & $1723(40.2)$ & $789(37.8)$ & $934(42.4)$ & \\
\hline Not anemic & $1808(42.1)$ & $942(45.1)$ & $866(39.3)$ & \\
\hline
\end{tabular}




\section{Table 3(on next page)}

Proportion of sample population with mild, moderate and severe anemia across the socioeconomic and demographic characteristics. GDHS 2008. 
Table 3: Proportion of sample population with mild, moderate and severe anemia across the socioeconomic and demographic characteristics. GDHS 2008.

\begin{tabular}{|c|c|c|c|c|}
\hline Variables & Severe & Moderate & Mild & $\mathrm{p}$ \\
\hline Age & & & & $<0.001$ \\
\hline $15-19$ & 8.8 & 22.3 & 24.2 & \\
\hline $20-24$ & 16.2 & 16.2 & 17.4 & \\
\hline $25-29$ & 10.3 & 16.8 & 14.9 & \\
\hline $30-34$ & 5.9 & 10.3 & 13.1 & \\
\hline $35-39$ & 17.6 & 15.8 & 13.1 & \\
\hline $40-44$ & 16.2 & 10.9 & 9.8 & \\
\hline $45-49$ & 25.0 & 7.8 & 7.7 & \\
\hline Marital status & & & & 0.690 \\
\hline Never married & 34.8 & 35.4 & 33.2 & \\
\hline Married & 47.8 & 41.6 & 45.9 & \\
\hline Living together & 10.1 & 12.7 & 11.3 & \\
\hline Other & 7.2 & 10.3 & 9.6 & \\
\hline Religion & & & & 0.684 \\
\hline Christian & 80.6 & 76.7 & 78.6 & \\
\hline Moslem & 14.9 & 16.4 & 14.0 & \\
\hline Other & 4.5 & 6.9 & 7.4 & \\
\hline Educational attainment & & & & 0.001 \\
\hline No education & 17.6 & 22.9 & 19.9 & \\
\hline Primary & 27.9 & 23.3 & 21.4 & \\
\hline Secondary & 52.9 & 50.5 & 56.1 & \\
\hline Higher & 1.5 & 3.3 & 2.6 & \\
\hline Wealth status & & & & 0.04 \\
\hline Poorest & 18.8 & 15.5 & 16.1 & \\
\hline Poorer & 23.2 & 17.5 & 19.9 & \\
\hline Middle & 24.6 & 24.3 & 22.8 & \\
\hline Richer & 21.7 & 21.7 & 20.1 & \\
\hline Richest & 11.6 & 21.1 & 21.2 & \\
\hline BMI & & & & $<0.001$ \\
\hline Underweight & 61.2 & 59.1 & 65.5 & \\
\hline Normal weight & 26.9 & 21.2 & 16.9 & \\
\hline Overweight & 10.4 & 11.4 & 8.1 & \\
\hline Obese & 1.5 & 8.2 & 9.5 & \\
\hline
\end{tabular}

N.B. $p$ calculated from chi-square tests. 


\section{Table 4 (on next page)}

Proportion of sample population with mild, moderate and severe anemia across the behavioral characteristics. GDHS 2008. 
Table 4: Proportion of sample population with mild, moderate and severe anemia across the behavioral characteristics. GDHS 2008.

\begin{tabular}{lcccc}
\hline & Severe & Moderate & Mild & p \\
\hline Alcohol consumption & & & & 0.283 \\
No & 83.8 & 82.6 & 82.9 & \\
Yes & 16.2 & 17.4 & 17.1 & \\
Smokes cigarettes & & & & 0.834 \\
No & 100.0 & 100.0 & 99.8 & \\
Yes & 0 & 0 & 0.2 & \\
Fruit consumption & & & & $<0.001$ \\
$<5$ servings/day & 72.1 & 88.1 & 96.6 & \\
5 or $>5$ servings/day & 27.9 & 11.9 & 3.4 & \\
Vegetable consumption & & & & $<0.001$ \\
$<5$ servings/day & 95.6 & 96.1 & 97.7 & \\
5 or $>5$ servings/day & 4.4 & 3.9 & 2.3 & \\
\cline { 1 - 3 } & & & &
\end{tabular}

N.B. $p$ calculated from chi-square tests. 


\section{Table 5 (on next page)}

Multivariate association between fruit and vegetable consumption and different levels of anemia among non-pregnant women in Ghana. GDHS 2008. 
Table 5: Multivariate association between fruit and vegetable consumption and different levels of anemia among non-pregnant women in Ghana. GDHS 2008.

\begin{tabular}{|c|c|c|c|c|c|c|}
\hline \multirow[b]{2}{*}{ (Urban sample) } & \multicolumn{2}{|c|}{ Severe } & \multicolumn{2}{|c|}{ Moderate } & \multicolumn{2}{|c|}{ Mild } \\
\hline & $\begin{array}{c}\text { POR } \\
(95 \% \mathrm{CI})\end{array}$ & $\begin{array}{c}\text { AOR } \\
(95 \% \mathrm{CI})\end{array}$ & $\begin{array}{c}\text { POR } \\
(95 \% \mathrm{CI})\end{array}$ & $\begin{array}{c}\text { AOR } \\
(95 \% \mathrm{CI})\end{array}$ & $\begin{array}{c}\text { POR } \\
(95 \% \mathrm{CI})\end{array}$ & $\begin{array}{c}\text { AOR } \\
(95 \% \mathrm{CI})\end{array}$ \\
\hline \multicolumn{7}{|l|}{ Fruit consumption } \\
\hline$\geq 5$ servings/day & & ref & & ref & & ref \\
\hline \multirow[t]{2}{*}{$<5$ servings/day } & 8.872 & 9.279 & 5.216 & 6.639 & 1.222 & 1.017 \\
\hline & (2.381- & (5.155- & (1.420- & (4.219- & $(0.279-$ & (0.607- \\
\hline \multicolumn{7}{|l|}{ Vegetable } \\
\hline \multicolumn{7}{|l|}{ consumption } \\
\hline$\geq 5$ servings/day & & ref & & ref & & ref \\
\hline \multirow[t]{3}{*}{$<5$ servings/day } & 5.308 & 3.708 & 2.007 & 2.386 & 1.765 & 0.910 \\
\hline & (1.542- & $(0.544-$ & $(0.664-6.070)$ & (1.135- & (0.554- & $(0.437-$ \\
\hline & 18.271) & 25.290) & & $5.018)$ & $5.624)$ & 1.896) \\
\hline \multicolumn{7}{|l|}{ F\&V consumption } \\
\hline$\geq 5$ servings/day & & ref & & ref & & ref \\
\hline \multirow[t]{3}{*}{$<5$ servings/day } & 1.677 & 1.011 & 1.684 & 0.867 & 0.605 & 0.971 \\
\hline & $(0.594-$ & $(0.570-$ & $(0.663-4.275)$ & $(0.708-$ & $(0.146-$ & $(0.831-$ \\
\hline & $4.735)$ & 1.793 & & $1.060)$ & $2.507)$ & $1.134)$ \\
\hline \multicolumn{7}{|l|}{ (Rural sample) } \\
\hline \multicolumn{7}{|l|}{ Fruit consumption } \\
\hline$\geq 5$ servings/day & & ref & & ref & & ref \\
\hline \multirow[t]{3}{*}{$<5$ servings/day } & 1.742 & 1.242 & 1.832 & 1.265 & 0.706 & 0.636 \\
\hline & $(0.419-$ & $(0.338-$ & (0.201- & $(0.712-$ & $(0.280-$ & $(0.386-$ \\
\hline & $7.250)$ & $4.563)$ & 16.660) & $2.246)$ & $1.782)$ & 1.048) \\
\hline \multicolumn{7}{|l|}{ Vegetable } \\
\hline \multicolumn{7}{|l|}{ consumption } \\
\hline$\geq 5$ servings/day & & ref & & ref & & ref \\
\hline \multirow[t]{3}{*}{$<5$ servings/day } & 1.962 & 1.409 & 1.607 & 1.236 & 1.674 & 1.301 \\
\hline & $(1.060-$ & $(0.211-$ & (0.887- & $(0.571-$ & (0.900- & $(0.700-$ \\
\hline & $3.635)$ & $9.398)$ & 2.909) & $2.678)$ & $3.112)$ & 2.417) \\
\hline \multicolumn{7}{|l|}{ F\&V consumption } \\
\hline$\geq 5$ servings/day & & ref & & ref & & ref \\
\hline$<5$ servings/day & 1.501 & 1.343 & 1.958 & 0.880 & 1.138 & 1.054 \\
\hline
\end{tabular}




\begin{tabular}{cccccc}
\hline$(0.806-$ & $(0.636-$ & $(0.517-$ & $(0.673-$ & $(0.841-$ & $(0.857-$ \\
$2.796)$ & $2.834)$ & $7.418)$ & $1.152)$ & $1.541)$ & $1.296)$ \\
\hline
\end{tabular}

N.B. Significant ORs were shown in bold. $P O R=$ partially adjusted odds ratio (adjusted for age, educational attainment, wealth status). AOR= Adjusted odds ratio (adjusted for age, educational attainment, wealth status, BMI). 